\title{
The OXIMAPA Study: Hypertension Control by ABPM and Association with Sleep Apnea Syndrome by Pulse Oximetry
}

\section{Estudo OXIMAPA: Controlo da Hipertensão por MAPA e Associação com Síndrome da Apneia do Sono por Oximetria}

Tiago MARICOTO $\rrbracket^{1}$, Eurico Alves Rodrigues SILVA¹, Pedro DAMIÃO ${ }^{1}$, José Mesquita BASTOS ${ }^{2}$

Acta Med Port 2017 Feb;30(2):93-99 - http://dx.doi.org/10.20344/amp.7495

ABSTRACT

Introduction: Ambulatory blood pressure monitoring by automatic device is the best blood pressure evaluation method and sleep apnea syndrome is the leading cause of poor control. Oximetry allows screening these individuals but its usefulness has been poorly explored in Primary Health Care. The aim was to evaluate the blood pressure control at the office and with ambulatory blood pressure monitoring by automatic device and to relate it to sleep apnea syndrome.

Material and Methods: We selected a sample of 50 participants, representative of 3036 hypertensive patients. The variables were: blood pressure value at the office and blood pressure with ambulatory blood pressure monitoring by automatic device; presence of criteria of sleep apnea syndrome in oximetry.

Results: The prevalence of uncontrolled blood pressure was $56 \%$ on office evaluation and $68 \%$ on ambulatory blood pressure monitoring by automatic device. It was found: $36 \%$ of daytime hypertension, $52 \%$ nocturnal hypertension, $40 \%$ non-dipper profile, $16 \%$ of white coat hypertension and $28 \%$ masked hypertension. The prevalence of sleep apnea syndrome was $16 \%$. Blood pressure in ambulatory blood pressure monitoring by automatic device and blood pressure in office showed no statistically significant association $(p=0.761)$. We found a statistically significant association between sleep apnea syndrome and daytime hypertension $(p=0.019)$ and non-dipper profile $(p=0.005)$.

Discussion and Conclusion: Ambulatory blood pressure monitoring by automatic device detected more $12 \%$ of uncontrolled hypertension than office blood pressure. Sleep apnea syndrome is strongly associated with uncontrolled hypertension and oximetry may be a good screening method, but should be studied further.

Keywords: Blood Pressure Monitoring, Ambulatory; Hypertension; Oximetry; Sleep Apnea Syndromes

\section{RESUMO}

Introdução: A monitorização ambulatorial da pressão arterial é o melhor método de avaliação da pressão arterial e a síndrome da apneia do sono é a principal causa de mau controlo. A oximetria permite rastrear estes indivíduos mas a sua utilidade tem sido pouco explorada em Cuidados de Saúde Primários. O objectivo foi avaliar o controlo da pressão arterial no consultório e na monitorização ambulatorial da pressão arterial, e relacioná-la com a síndrome da apneia do sono.

Material e Métodos: Selecionou-se uma amostra de 50 participantes, representativa de 3036 doentes hipertensos. As variáveis avaliadas foram: valor de pressão arterial no consultório e na monitorização ambulatorial da pressão arterial; presença de critérios de síndrome da apneia do sono na oximetria.

Resultados: A prevalência de pressão arterial não controlada foi de $56 \%$ no consultório e $68 \%$ na monitorização ambulatorial da pressão arterial. Encontrou-se: $36 \%$ de hipertensão diurna, $52 \%$ de hipertensão nocturna, $40 \%$ de perfil não-dipper, $16 \%$ de hipertensão da bata-branca e $28 \%$ de hipertensão mascarada. A prevalência de síndrome da apneia do sono foi $16 \%$. A pressão arterial no consultório e na monitorização ambulatorial da pressão arterial não mostrou associação estatisticamente significativa $(p=0,761)$. Encontrou-se uma associação estatisticamente significativa entre síndrome de apneia do sono e hipertensão diurna $(p=0,019)$ e perfil não-dipper $(p=0,005)$.

Discussão e Conclusão: A monitorização ambulatorial da pressão arterial detetou mais $12 \%$ de casos de hipertensão não controlada do que o consultório. A síndrome da apneia do sono está fortemente associada a hipertensão não controlada e a oximetria pode ser um bom método de rastreio, mas deve ser mais estudada.

Palavras-chave: Hipertensão; Monitorização Ambulatória da Pressão Arterial; Oximetria; Síndromes da Apneia do Sono

\section{INTRODUCTION}

High blood pressure (HBP) is a disease with great worldwide prevalence and incidence, contributing significantly towards high morbidity and mortality in developed countries. Stroke is the leading cause of death in Portugal, probably due to the reduced control of blood pressure (BP) ${ }^{1}$ and high salt intake. ${ }^{2}$ According to Portuguese data it is estimated that approximately $42 \%$ of the population is hypertensive. ${ }^{3,4}$ Among the diagnosed

hypertensive patients the adherence rate reaches $84.8 \%{ }^{3}$ but only between $28.6 \%$ and $42.5 \%$ of these are controlled. ${ }^{3,4}$

Addressing the HBP has been a challenge once the less typical presentations create difficulties in diagnosis and control. An example is the white coat hypertension, it is found in $20 \%$ to $70 \%$ of the diagnosed and treated patients. ${ }^{5}$ In other patients the nocturnal BP seems to be controlled but they do not exhibit the physiological decrease expected

\footnotetext{
1. Family Medicine and General Practice. Unidade de Cuidados de Saúde Personalizados Aveiro I. Aveiro. Portugal.

2. Cardiology Department. Centro Hospitalar do Baixo Vouga. Aveiro. Portugal.

$\triangle$ Autor correspondente: Tiago Maricoto. tiago.maricoto@gmail.com

Recebido: 07 de fevereiro de 2016 - Aceite: 22 de agosto de 2016 | Copyright @ Ordem dos Médicos 2017
} 
during nighttime, which, in healthy individuals with lower cardiovascular risk (CVR), is generally about $10 \%$ to $20 \%$ of the daytime values. This phenomenon affects up to $25 \%$ of the general population, ${ }^{6}$ but it can reach even more in some specific sub-groups, such as obese children. ${ }^{7}$ This is the non-dipper profile and its prevalence in hypertensive patients can reach $60 \%$ in primary care. ${ }^{8}$ The nocturnal $\mathrm{BP}$ represents the greatest prognostic value for $\mathrm{CVR}^{9,10}$ and in all these atypical forms of presentation this risk increases. $^{11-17}$

There are several available techniques for the hypertension diagnosis and control, including the evaluation in medical office, ambulatory self-measurement and ambulatory blood pressure monitoring by automatic device (ABPM). Several studies and international guidelines refer to the ABPM as an essential tool in the evaluation and control of hypertension, and therefore it is a good indicator of cardiovascular risk, exhibiting the best efficacy and costeffectiveness, ${ }^{18-20}$ including in the Portuguese population. ${ }^{21}$ Some authors reinforced its importance in the Primary Health Care (PHC) by suggesting that it should be available for family doctors' use. .2,23 $^{2}$

Several studies attempted to elucidate the mechanisms underlying resistant $\mathrm{HBP}$ and its different types of presentation, and obstructive sleep apnea syndrome (SAS) is possibly the main secondary cause, especially the obstructive form which may occur in about $80 \%$ of the patients. ${ }^{24,25}$ SAS is often asymptomatic and the global prevalence can reach $30 \%$. There is a strong association between SAS and daytime high blood pressure, nocturnal HBP and non-dipper profile. ${ }^{24-26}$ It is one of the main predictors of increased CVR in patients with HBP, and the pathophysiological mechanism may be through hypoxemia phenomenon. ${ }^{24-26}$ Polysomnography (PSG) is the best test for diagnosing sleep apnea syndrome, especially to distinguish between obstructive and central form, however, due to its limited availability in $\mathrm{PHC}$, the nocturnal pulse oximetry is recommended as a great method to screen these patients. It achieves sensitivity up to $98 \%$ and some evidence of its validity is emerging. ${ }^{27-32}$ The European Respiratory Society also recommends an evaluation with ABPM in hypertensive patients showing obstructive apnea. ${ }^{32}$ Despite being well explored in Secondary Health Care, few studies were performed in the Portuguese Primary Health Care to assess the utility of ambulatory blood pressure monitoring by automatic device in the control of hypertensive patients, as well as the association between HBP and sleep apnea syndrome.

The aim of this study was to describe the hypertensive population of a Portuguese Health Centre unit regarding the control of blood pressure, either through ABPM and office evaluation, and to relate different profiles of uncontrolled HBP with sleep apnea syndrome, screened by nocturnal pulse oximetry.

\section{MATERIAL AND METHODS Study design}

An observational, descriptive and analytical study was carried out in a Portuguese health center unit of Aveiro. Inclusion criteria were: adult patients diagnosed with hypertension (with or without complications) and treated with, at least, one class of antihypertensive drugs. Exclusion criteria were: non-adherence to antihypertensive therapy during the study conduction or in the previous three weeks, clinical severe acute condition and the use of noninvasive breathing assistance device. It was applied a case-control design for the data analysis. All participants signed an informed consent.

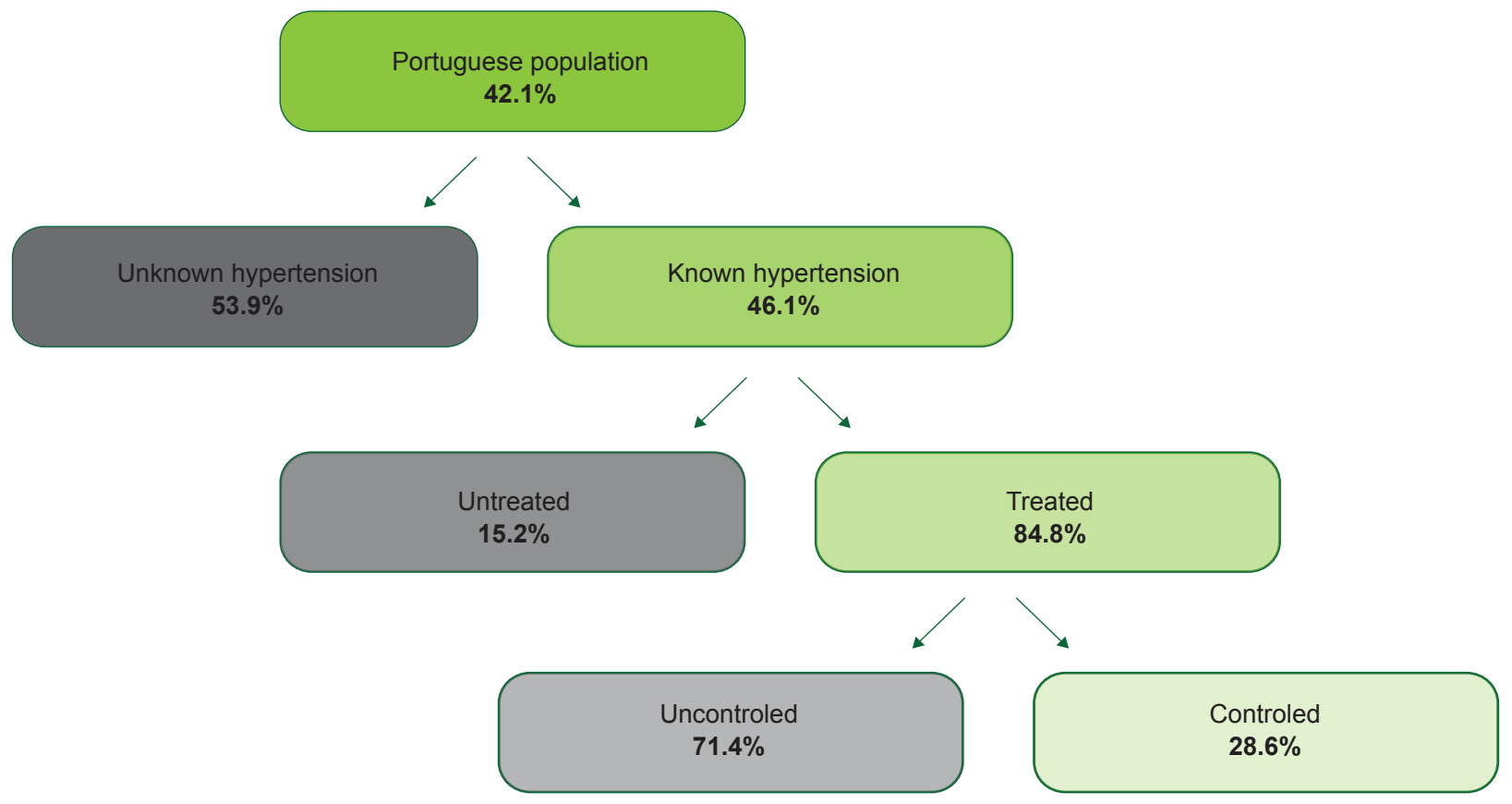

Figure 1 - Epidemiologic prevalence data of hypertension in Portugal (data adapted from Barros P et al, 2007) ${ }^{1}$ 


\section{Sample size assessment}

A statistically representative sample was calculated, set from a target population of 3036 hypertensive individuals registered in the Aveiro health center. To ensure the statistical representativeness of the sample, we used the online free access tool Epilnfo (weblink: www.openepi. com) to calculate it and all participants were selected by simple random sampling with replacement. Individuals with controlled HBP were considered as 'control', with an estimated prevalence of $28.6 \%$ among treated patients, and as 'cases', individuals with poorly controlled HBP, estimated in $71.4 \%$. These prevalence rates were used to sample size calculation. A 95\% confidence interval with $\beta$ value (power) of $80 \%$ and a ratio of cases/controls of $1: 1$ were established. At last, the sample size was readjusted for excess, considering the estimated proportion of adherence and full compliance of the study (70\% default), as well as treatment adherence $(84.8 \%$ of patients diagnosed with HBP). Fig. 1 summarizes the epidemiological data for the Portuguese population ${ }^{1}$ considered in this calculation and Fig. 2 shows the used mathematical equation to the sample size readjustment, estimating a complete sample size of 89 individuals. Table 1 summarizes baseline characteristics and the participants selection process.

\section{Variables}

Three nominal qualitative variables were defined: the evaluation of BP in the office; BP using the ABPM; and

$$
\mathrm{n}=\frac{\mathrm{n} 0}{\mathrm{p} 1 \times \mathrm{p} 2}
$$

$\mathrm{n}$ : Readjusted final sample size;

n0: Sample size initially calculated;

p1: Fraction of treatment adherence (0.848);

p2: Fraction of adherence and full compliance with the study (0.7)

Figure 2 - Adjusted sample size calculation formula

the presence of SAS criteria in oximetry. Table 2 shows the maximum BP values considered normal for the control group, as well as the values of the oxygen desaturation index - ODI (average number of desaturation events per hour, during 10 seconds each). For ODI values two cutoff points were used, one was representing $100 \%$ sensitivity for the diagnosis of SAS and the other one was representing $100 \%$ specificity for its exclusion. Therefore, by setting these cutoff points, it is statistically implied the rational presumption of diagnosis, either for its confirmation or exclusion. However, all the intermediate results that did not fulfill these criteria were defined as uncertain for the diagnosis of SAS. Thus, three different profiles were defined: positive, uncertain, and negative oximetry results for SAS. It was not assessed the presence of symptoms or clinical findings suggestive of SAS. Different HBP profiles were also defined:

Table 1 - Description of baseline characteristics and the participants' selection

\begin{tabular}{lr}
\hline $\begin{array}{l}\text { Target Population } \\
\text { (Hypertensive patients registered in the Aveiro Health Center unit by July 2013) }\end{array}$ & 3036 \\
\hline $\begin{array}{l}\text { Number of participants randomized and invited to participate } \\
\text { Number of excluded participants }\end{array}$ & 89 \\
Do not attended or did not fulfill inclusion criteria & 39 \\
Missed the scheduled date or rejected to participate & 24 \\
Number of obtained participants & 50 \\
Baseline Characteristics & 50 \\
Males $(\%)$ & $63.48( \pm 11.11)$ \\
Mean Age $( \pm$ sd) & $29.37( \pm 4.64)$ \\
Mean BMI $( \pm$ sd) & \\
\hline
\end{tabular}

BMI: Body Mass Index $\left(\mathrm{Kg} / \mathrm{m}^{2}\right)$

Table 2 - Criteria defined to the operationalization of variables studied

\begin{tabular}{|c|c|c|c|c|}
\hline & & & Systolic BP $(\mathrm{mmHg})^{*}$ & Diastolic BP $(\mathrm{mmHg})^{*}$ \\
\hline \multirow[t]{2}{*}{ Office } & & & 140 & 90 \\
\hline & Global (24h) & & 130 & 80 \\
\hline \multirow[t]{4}{*}{ ABPM } & Day time $(07$ & 23h) & 135 & 85 \\
\hline & Night time ( & $-07 \mathrm{~h})$ & 120 & 70 \\
\hline & \multicolumn{3}{|c|}{ ODI } & \\
\hline & Positive & \multicolumn{3}{|c|}{ If superior than 32 for decreases of $3 \%$ in $\mathrm{O}_{2}$ Sat OR superior than 4.3 for decreases of $5 \%$ in $\mathrm{O}_{2}$ Sat } \\
\hline \multirow[t]{2}{*}{ Oximetry } & Uncertain & \multicolumn{3}{|c|}{ Intermediate values } \\
\hline & Negative & \multicolumn{3}{|c|}{ If inferior than 12.2 for decreases of $2 \%$ in $\mathrm{O}_{2}$ Sat } \\
\hline
\end{tabular}

ODI: Oxygen desaturation index (events/hour); $\mathrm{O}_{2}$ Sat: Oxygen pulse saturation in \%

* The values refer to the average blood pressure (BP) obtained and define the maximum limits to consider the variable as 'controlled' 
daytime, nocturnal, masked, white coat and non-dipper. The limits to define uncontrolled BP were set for BP according to the guidelines of the National Institute for Health and Clinical Excellence, 2011,20 the European Society of Hypertension (ESH), $2005^{33}$ and the Portuguese clinical guideline of the General Health Directorate (DGS) 020/2011 for HBP. ${ }^{34}$ Although there are different concepts of 'uncontrolled HBP' (BP levels above $140 / 90 \mathrm{mmHg}$ regardless the number of drugs and secondary causes) and 'resistant HBP' (BP levels above 140/90 mmHg despite taking three different drugs), ${ }^{25}$ we did not use any classification to differentiate participants. The guidelines followed to evaluate the oximetry were set by the American Academy of Sleep Medicine 2012, ${ }^{31}$ the European Respiratory Society $2013^{32}$ and the oximeter validation study. ${ }^{35}$ ABPM was performed in a regular active day for a period of 24 hours through the validated SPACELABS HEALTHCARE ${ }^{\circledR}$ device, model $90217 \mathrm{~A},{ }^{36}$ in the same arm on which the office evaluation was performed. The oximetry was collected using a finger sensor and performed through the validated device WristOx ${ }^{\circledR}$, model 3150 SK $-04 .{ }^{35}$ The office BP values were obtained in two moments, one before and the other after the implementation of the ABPM device. A minimum of three measurements on each day were taken and the first measurement of each one was excluded. The final used value was the arithmetic average of the remaining four measurements.

Data were analyzed using IBM SPSS Statistics $20^{\circledR}$. Descriptive statistics were used to calculate the HBP and the SAS prevalence and analytical tests were used for the different variables association. The quantitative variables were tested for normal distribution using KolmogorovSmirnov and compared using One-way ANOVA test. The qualitative variables are presented in contingency table, using the Fisher's exact test and calculating the odds ratio (OR).

\section{RESULTS}

Fifty volunteers participated in the study, $25(50 \%)$ women and $25(50 \%)$ men with a mean age of $63.48( \pm$

Table 3 - Prevalence results of different profiles found in office BP, ABPM and Oximetry [in \% (No.)]

\begin{tabular}{lcc}
\hline & Office & ABPM \\
\hline Controlled HBP & $44 \%(22)$ & $32 \%(16)$ \\
Uncontrolled HBP & $56 \%(28)$ & $68 \%(34)$ \\
Daytime HBP & $36 \%(18)$ \\
Nocturnal HBP & $52 \%(26)$ \\
Non-dipper profile & $40 \%(20)$ \\
White coat HBP & $16 \%(8)$ \\
Masked HBP & $28 \%(14)$ \\
\hline & \multicolumn{2}{c}{ Oximetry } \\
\hline Positive criteria for SAS & $16 \%(8)$ \\
Uncertain criteria for SAS & $16 \%(8)$ \\
Negative criteria for SAS & $68 \%(34)$ \\
\hline
\end{tabular}

ABPM: Ambulatory blood pressure monitoring; HBP: High blood pressure; SAS: Sleep apnea syndrome
11.11) years and mean body mass index (BMI) of 29.37 ( \pm $4.64) \mathrm{kg} / \mathrm{m}^{2}$. Regarding the anti-hypertensive drug classes, $22(44 \%)$ participants were treated with diuretics, $22(44 \%)$ with angiotensin converting enzyme inhibitor, 19 (38\%) with angiotensin receptor antagonist, $14(28 \%)$ with calcium channel antagonist, four ( $8 \%$ ) with a beta blocker, one $(2 \%)$ with a nitrate and one (2\%) with an alpha blocker. Twenty two (44\%) patients were treated with only one drug, 23 (46\%) with two drugs and five (10\%) with three drugs. There were no significant differences in BMI between different groups of oximetry results ( $p=0.09$, independent samples $t$ test).

The oximetry results and the prevalence of different BP profiles obtained in the office evaluation and ABPM are in Table 3. In addition to the eight (16\%) patients with positive criteria in oximetry for diagnosis of SAS, eight more participants showed uncertain results, however they were not included in the statistical tests for the association of these variables.

Contingency Table 4 shows the results of the BP assessment in ABPM and office and no significant association was found between them ( $p=0.76$, Fisher's exact test). Table 5 shows the association between SAS and the several blood pressure profiles in HBPM. Despite no statistically significant association was found between SAS and nocturnal high blood pressure, among the 20 participants with nocturnal HBP, nine of them reported poor sleep quality, and in fact, after exclusion of these cases this association acquires a statistical significance $(p=0.049$, Fisher's exact test). There was also an association between SAS and daytime HBP and non-dipper profile, respectively, with statistically significant associations found $(p=0.019$ and $p=0.005$ respectively, Fisher's exact test).

Table 6 shows the mean BP levels (in office and in ABPM) and the mean \% of nocturnal dipping, between the various groups of oximetry results. There were found significant differences between the three groups in the global systolic blood pressure in ABPM and in the mean \% of nocturnal dipping, suggesting that the SAS group have worse parameters. These findings are consistent with the previous ones, when these variables were converted in quantitative set. Despite this, the same relationship was not found between diastolic BP values and SAS.

\section{DISCUSSION AND CONCLUSION HBP profiles and control}

In this study, the prevalence of uncontrolled HBP was $68 \%$, similar to that reported in the Portuguese literature, which is between $57.5 \%$ and $71.4 \%{ }^{3,4}$ Among its different profiles, the prevalence of white coat HBP (16\%) was slightly below other bibliographic reports, between 20 and $70 \% .^{5}$ Regarding this fact, although some researchers suggest an association with higher CVR, the controversy on the benefit of treating such patients remains. ${ }^{37}$ In our study, the prevalence of non-dipper profile (40\%) was similar to the ones reported in other surveys (between $25 \%$ to $60 \%)$. 6,7 The occurrence of masked HBP $(28 \%$ in our study) was relatively high, revealing the cases that are 
Table 4 - Association between BP measurement in ABPM and in office

\begin{tabular}{|c|c|c|c|c|}
\hline & & \multicolumn{2}{|c|}{$B P$ in ABPM } & \multirow{2}{*}{ Total } \\
\hline & & Uncontrolled & Controlled & \\
\hline \multirow{2}{*}{ BP in Office } & Uncontrolled & 20 & 8 & 28 \\
\hline & Controlled & 14 & 8 & 22 \\
\hline Total & & 34 & 16 & 50 \\
\hline
\end{tabular}

Fisher's exact test: $p=0.761$; Odds ratio $=1.43$

ABPM: Ambulatory blood pressure monitoring; BP: Blood pressure

Table 5 - Association between SAS and: nocturnal HBP, Daytime HBP and non-dipper profile.

\begin{tabular}{|c|c|c|c|c|c|c|}
\hline & & \multicolumn{2}{|c|}{ Positive criteria for SAS } & \multirow{2}{*}{ Total } & \multirow{2}{*}{$p$ value $^{*}$} & \multirow{2}{*}{ Odds Ratic } \\
\hline & & No & Yes & & & \\
\hline \multirow{2}{*}{ Nocturnal HBP } & No & 22 & 2 & 24 & \multirow{3}{*}{0.25} & \multirow{3}{*}{3.3} \\
\hline & Yes & 20 & 6 & 26 & & \\
\hline Total & & 42 & 8 & 50 & & \\
\hline \multirow{2}{*}{ Daytime HBP } & No & 30 & 2 & 32 & \multirow{3}{*}{0.019} & \multirow{3}{*}{7.5} \\
\hline & Yes & 12 & 6 & 18 & & \\
\hline Total & & 42 & 8 & 50 & & \\
\hline \multirow{2}{*}{ Non-dipper profile } & No & 29 & 1 & 30 & \multirow{3}{*}{0.005} & \multirow{3}{*}{15.6} \\
\hline & Yes & 13 & 7 & 20 & & \\
\hline Total & & 42 & 8 & 50 & & \\
\hline
\end{tabular}

HBP: High blood pressure; SAS: Sleep apnea syndrome

* Fisher's exact test

Table 6 - Blood Pressure levels between the various groups of oximetry

\begin{tabular}{|c|c|c|c|c|}
\hline & \multicolumn{3}{|c|}{ Oximetry result } & \multirow{2}{*}{$p$ value* } \\
\hline & Negative for SAS & Uncertain for SAS & Positive for SAS & \\
\hline \multicolumn{5}{|c|}{ Mean systolic BP values $[( \pm \mathrm{sd}), \mathrm{mmHg}]$} \\
\hline In office & $143.4( \pm 15)$ & $149.5( \pm 21.3)$ & $161.6( \pm 36)$ & 0.084 \\
\hline \multicolumn{5}{|l|}{ In ABPM } \\
\hline Day time & $129.6( \pm 10.9)$ & $132.4( \pm 12.2)$ & $143.8( \pm 20)$ & 0.026 \\
\hline Night time & $113.1( \pm 14.5)$ & $122.8( \pm 11.8)$ & $136.8( \pm 21.9)$ & $<0.001$ \\
\hline \multicolumn{5}{|c|}{ Mean diastolic BP values $[( \pm \mathbf{s d}), \mathrm{mmHg}]$} \\
\hline In office & $78.9( \pm 10.7)$ & $78.6( \pm 11.2)$ & $79( \pm 14.5)$ & 0.997 \\
\hline \multicolumn{5}{|l|}{ In ABPM } \\
\hline Day time & $76.3( \pm 9.1)$ & $78.4( \pm 10.2)$ & $76.5( \pm 7.7)$ & 0.846 \\
\hline Night time & $64.2( \pm 9.2)$ & $70.5( \pm 8.6)$ & $70.3( \pm 5.5)$ & 0.074 \\
\hline$\%$ of Dipping in MBP & $13.3( \pm 7.8)$ & $8.5( \pm 7.3)$ & $5.8( \pm 3.9)$ & 0.022 \\
\hline
\end{tabular}

ABPM: Ambulatory blood pressure monitoring; BP: Blood pressure; MBP: Mean blood pressure; SAS: Sleep apnea syndrome

* One-way ANOVA test

not easily diagnosed only through BP measurements in office, however this prevalence was lower than is the one reported by Konstantopoulou AS et al, 2006 (up to 42\%). ${ }^{15}$ Considering nocturnal HBP as an important marker of CVR,,${ }^{9,10}$ a significant prevalence (52\%) was found in our study.

\section{SAS Prevalence}

Comparing with other studies worldwide, with a prevalence ranging from 30 to $80 \%,{ }^{24,25}$ in this study the prevalence of SAS was low (16\%). A low prevalence was also reported in 2014 in a Portuguese study performed by the DGS that found $1 \%$ in the general population; however the authors assumed that this value could be underestimated due to several reasons, highlighting the lack of adequate clinical records. ${ }^{38}$ Despite the growing scientific evidence to sustain oximetry validity and utility, ${ }^{27-31,39}$ it is not the reference exam (gold standard) for SAS diagnosis. In order to evaluate the oximetry results, we used a method with two different cutoff points, one representing $100 \%$ of sensitivity for the diagnosis and the other one representing $100 \%$ of specificity for the diagnosis exclusion. Therefore, between these two cutoff points there is an intermediate range of uncertain values which must be confirmed with PSG. For this reason, the obtained prevalence might be underestimated. In fact, beyond these eight positive cases 
(with 100\% sensitivity) other eight uncertain cases were obtained, these could increase the real prevalence up to $32 \%$ if they were confirmed as SAS, similarly to the reported bibliography.

\section{Measuring BP in office and AMBP}

A significant similarity between measuring BP in ABPM and measuring it in office was not found, and this means that these two methods are not equivalent (Table 4). Thus, ABPM has detected more $12 \%$ (six cases) of uncontrolled hypertensive patients compared to the office BP, suggesting that ABPM assessment is greater than the office evaluation regarding the diagnostic sensitivity, similar to what has been stated in several studies. ${ }^{18-20}$ ABPM also provides valuable data for the CVR approach, such as blood pressure load $^{40}$ and pulse pressure ${ }^{41}$ and, also with some growing evidence, the variability of blood pressure ${ }^{42}$ and the morning surge,${ }^{43}$ however this was not assessed in our study.

\section{Association between SAS and uncontrolled HBP}

A strong association was found between sleep apnea syndrome and uncontrolled daytime HBP, as well as between SAS and non-dipper profile (Tables 5), which supports the published literature. ${ }^{12,13}$ Nevertheless, this association was not found with nocturnal HBP, which can be explained by the fact that almost half of the participants showing this profile have reported poor sleep quality during the examination and might be false positives. This phenomenon has been described by other authors, ${ }^{44}$ but, although in this study it was not evaluated by the proper scales and tools, the participants might have been in light sleep or might had frequent awakenings, masking this association. Moreover, these cases may also represent false negative for SAS, being hidden by the failure to achieve a physiological deep sleep. By excluding these cases, the association between nocturnal HBP and SAS becomes statistically significant, similar to what was reported in the studies mentioned previously.

Beyond the eight positive cases of SAS detected by oximetry, other eight uncertain cases were obtained, as mentioned above. Among these additional cases, two had normal ABPM, but six had abnormal ABPM, predominating nocturnal HBP $(n=6)$ and non-dipper profile $(n=5)$. Furthermore, in a post-hoc analysis, the differences in systolic BP values and in \% of nocturnal dipping between the various oximetry groups (Table 6 ) were only significant between the positive and the negative group. The uncertain cases of SAS showed, in almost every parameter, intermediate BP values between the negative and the positive groups. They can represent some mild form of SAS, not enough significant to be detected by oximetry, but serious enough to affect blood pressure control, once only two cases had ABPM values under the normal cutoff. This means that the lack of statistical significance in the association between sleep apnea syndrome and nocturnal HBP (Table 5) may actually exist and can become more evident if the uncertain cases of SAS are confirmed as sleep apnea syndrome. The small sample size, despite it is statistically representative of a larger target population, may also have compromised these results.

\section{Limitations}

Beyond the limitations already mentioned others should be remarked. Our study was not blind, since it design and methodology made it unenforceable, so it may exist an observer and participant bias. The prevalence of pure resistant hypertension was not evaluated by the ESH criteria, which, despite being low, may not be related to SAS. Although there is a strong association between SAS and uncontrolled HBP, there might be other causes of uncontrolled HBP that are not contemplated here.

\section{Final remarks}

This work reinforces the importance of ABPM in the control of high blood pressure and in the detection of different profiles which otherwise go undetected, such as nocturnal high blood pressure, masked HBP, white coat high blood pressure and the non-dipper profile. The results suggest that ABPM assessment is greater than the BP in office, and may have up to $12 \%$ more sensitivity. The prevalence of SAS is significant and this is related with uncontrolled HBP. Although SAS should be considered as a diagnostic hypothesis in the presence of suggestive clinical findings, the pulse oximetry can be an effective method for its detection and screening, and should be further explored and tested, with strong and well-designed studies with larger samples. The ABPM and pulse oximetry are complementary diagnostic methods, which should be considered simultaneously in a first HBP patient approach. These methods are in the scope of PHC and may be useful as appropriate tools for family doctors use in their clinical practice.

\section{PROTECTION OF HUMANS AND ANIMALS}

The authors declare that the procedures were followed according to the Helsinki Declaration of the World Medical Association.

\section{DATA CONFIDENTIALITY}

The authors declare having followed the protocols in use at their working center regarding patients' data publication.

\section{CONFLICTS OF INTEREST}

The authors declare that there are no conflicts of interest.

\section{FUNDING SOURCES}

The authors declare and acknowledge the Portuguese Association of Family Medicine and General Practice ${ }^{\odot}$ and the AstraZeneca ${ }^{\odot}$ company for the support provided by funding this work within the context of "APMGF/AstraZeneca research grant 2013 - Primary Health Care". The received funding was an "unrestricted grant", which means that the sponsor had no influence either in the scientific methodology or the final contents of this work. 


\section{REFERENCES}

1. Barros P, de Almeida Simões J. Portugal: Health system review. Health Syst Transit. 2007;9:1-140.

2. Polonia J, Martins L. A comprehensive review on salt and health and current experience of worldwide salt reduction programmes. J Hum Hypertens. 2009;23:771-2.

3. De Macedo ME, Lima MJ, Silva AO, Alcântara $P$, Ramalhinho $V$, Carmona J. Prevalência, conhecimento, tratamento e controlo da hipertensão em Portugal. Estudo PAP. Rev Port Cardiol. 2007;26:21-39.

4. Polonia J, Martins L, Pinto F, Nazare J. Prevalence, awareness, treatment and control of hypertension and salt intake in Portugal: changes over a decade. The PHYSA study. J Hypertens. 2014;32:121121.

5. MacDonald MB, Laing GP, Wilson MP, Wilson TW. Prevalence and predictors of white-coat response in patients with treated hypertension. CMAJ. 1999;161:265-9.

6. Coleman CT, Stowasser M, Jenkins C, Marwick TW, Sharman JE. Central hemodynamics and cardiovascular risk in nondippers. J Clin Hypertens. 2011;13:557-62.

7. Török K, Pálfi A, Szelényi Z, Molnár D. Circadian variability of blood pressure in obese children. Nutr Metab Cardiovasc Dis. 2008;18:42935.

8. Gorostidi M, Sobrino J, Segura J, Sierra C, de la Sierra A, del Rey RH, et al. Ambulatory blood pressure monitoring in hypertensive patients with high cardiovascular risk: a cross-sectional analysis of a 20,000-patient database in Spain. J Hypertens. 2007;25:977-84.

9. Mesquita-Bastos J, Bertoquini S, Polónia J. Cardiovascular prognostic value of ambulatory blood pressure monitoring in a Portuguese hypertensive population followed up for 8.2 years. Blood Press Monit. 2010;15:240-6.

10. Fagard RH, Celis H, Thijs L, Staessen JA, Clement DL, de Buyzere ML, et al. Daytime and nighttime blood pressure as predictors of death and cause-specific cardiovascular events in hypertension. Hypertension. 2008;51:55-61.

11. Fan H, Li Y, Thijs L, Hansen TW, Boggia J, Kikuya M, et al. Prognostic value of isolated nocturnal hypertension on ambulatory measurement in 8711 individuals from 10 populations. J Hypertens. 2010;28:2036-45.

12. Birkenhäger $A M$, van den Meiracker $A H$. Causes and consequences of a non-dipping blood pressure profile. Neth J Med. 2007;65:127-31.

13. Ben-Dov IZ, Kark JD, Ben-Ishay D, Mekler J, Ben-Arie L, Bursztyn M. Blunted heart rate dip during sleep and all-cause mortality. Arch Intern Med. 2007;167:2116-21.

14. Benetos A, Rudnichi A, Safar M, Guize L. Pulse pressure and cardiovascular mortality in normotensive and hypertensive subjects. Hypertension. 1998;32:560-4.

15. Konstantopoulou AS, Papargyriou IK, Antoniadou IS, Konstantopoulou PS, Papadogiannis DE. Masked hypertension: a new entity under investigation. Hellenic J Cardiol. 2006;47:232-5.

16. Conen D, Bamberg F. Noninvasive 24-h ambulatory blood pressure and cardiovascular disease: a systematic review and meta-analysis. J Hypertens. 2008;26:1290-9.

17. Hansen TW, Kikuya M, Thijs L, Björklund-Bodegård K, Kuznetsova $\mathrm{T}$, Ohkubo $\mathrm{T}$ Prognostic superiority of daytime ambulatory over conventional blood pressure in four populations: a meta-analysis of 7030 individuals. J Hypertens. 2007;25:1554-64.

18. Conen D, Bamberg F. Noninvasive 24-h ambulatory blood pressure and cardiovascular disease: a systematic review and meta-analysis. J Hypertens. 2008;26:1290-9.

19. National Institute for Health and Clinical Excellence. Hypertension. The clinical management of primary hypertension in adults. London: NICE; 2011.

20. Krakoff LR. Cost-effectiveness of ambulatory blood pressure. A reanalysis. Hypertension. 2006;47:29-34.

21. Mesquita-Bastos J, Bertoquini S, Polónia J. Cardiovascular prognostic value of ambulatory blood pressure monitoring in a Portuguese hypertensive population followed up for 8.2 years. Blood Press Monit. 2010;15:240-6.

22. O`Brien E. Ambulatory blood pressure measurement. The case for implementation in primary care. Hypertension. 2008;51:1435-41.

23. Parati G, Stergiou G, O'Brien E, Asmar R, Beilin L, Bilo G, et al. European Society of Hypertension Working Group on Blood Pressure Monitoring and Cardiovascular Variability. European Society of Hypertension practice guidelines for ambulatory blood pressure monitoring. Hypertens. 2014;32:1359-66

24. Somers VK, White DP, Amin R, Abraham WT, Costa F, Culebras A, et al. Sleep apnea and cardiovascular disease. J Am Coll Cardiol. 2008;52:686-717.

25. Pedrosa RP, Drager LF, Gonzaga CC, Sousa MG, de Paula LK, Amaro $A C$, et al. Obstructive sleep apnea: the most common secondary cause of hypertension associated with resistant hypertension. Hypertension. 2011;58:811-7.

26. Mannarino MR, Filippo FD, Pirro M. Obstructive sleep apnea syndrome. Eur J Int Med. 2012;23:586-93.

27. Sériès F, Marc I, Cormier Y, La Forge J. Utility of nocturnal home oximetry for case finding in patients with suspected sleep apnea hypopnea syndrome. Ann Intern Med. 1993;119:449-53.

28. Rofail LM, Wong KK, Unger G, Marks GB, Grunstein RR. Comparison between a single-channel nasal airflow device and oximetry for the diagnosis of obstructive sleep apnea. Sleep. 2010;33:1106-14.

29. Sommermeyer D, Zou D, Grote L, Hedner J. Detection of sleep disordered breathing and its central/obstructive character using nasal cannula and finger pulse oximeter. J Clin Sleep Med. 2012;8:527-33.

30. Fleetham J, Ayas N, Bradley D, Fitzpatrick M, Oliver TK, Morrison D, et al. Canadian Thoracic Society 2011 guideline update: diagnosis and treatment of sleep disordered breathing. Can Respir J. 2011;18:25-47.

31. Berry RB, Budhiraja R, Gottlieb DJ, Gozal D, Iber C, Kapur VK, et al. Rules for scoring respiratory events in sleep: update of the 2007 AASM Manual for the Scoring of Sleep and Associated Events. Deliberations of the Sleep Apnea Definitions Task Force of the American Academy of Sleep Medicine. J Clin Sleep Med. 2012;8:597-619.

32. Parati G, Lombardi C, Hedner J, Bonsignore MR, Grote L, Tkacova R, et al. Recommendations for the management of patients with obstructive sleep apnoea and hypertension. Eur Respir J. 2013;41:523-38.

33. O`Brien E, Asmar R, Beilin L. Practice guidelines of the European Society of Hypertension for clinic, ambulatory and self-blood pressure measurement. J Hypertens. 2005;23:697-701.

34. Direcção Geral de Saúde. Hipertensão Arterial: definição e classificação. Norma de orientação clínica 020.2011. Reviewed at 19/03/2013. Lisboa: DGS; 2013.

35. Nigro CA, Aimaretti S, Gonzalez S, Rhodius E. Validation of the WrisOx $3100^{\mathrm{TM}}$ oximeter for the diagnosis of sleep apnea/hypopnea syndrome. Sleep Breath. 2009;13:127-36.

36. Baumgart P, Kamp J. Accuracy of the Spacelabs Medical 90217 ambulatory blood pressure monitor. Blood Press Monit. 1998;3:303-7.

37. Mancia G, Facchetti R, Parati G, Zanchetti A. Effect of long-term antihypertensive treatment on white-coat hypertension. Hypertension. 2014;64:1388-98.

38. Rodrigues AP, Pinto P, Nunes B, Bárbara C. Síndrome de apneia obstrutiva do sono: epidemiologia, diagnóstico e tratamento. Um estudo da Rede Médicos-Sentinela. Direcção Geral de Saúde. 2014. [acedido 2015 Mar 3] Disponível em: http://www.dgs.pt.

39. Romem A, Romem A, Koldobskiy D, Scharf SM. Diagnosis of obstructive sleep apnea using pulse oximeter derived photoplethysmographic signals. J Clin Sleep Med. 2014;10:285-90.

40. National Heart Foundation and High Blood Pressure Research Council of Australia Ambulatory Blood Pressure Monitoring Consensus Committee. Ambulatory blood pressure monitoring. Aust Fam Physician. 2011;40:877-90.

41. Verdecchia P, Schillaci G, Borgioni C, Ciucci A, Pede S, Porcellati C. Ambulatory pulse pressure: a potent predictor of total cardiovascular risk in hypertension. Hypertension. 1998;32:983-8.

42. Palatini P, Reboldi G, Beilin LJ, Casiglia E, Eguchi K, Imai Y, et al. Added predictive value of night-time blood pressure variability for cardiovascular events and mortality: the Ambulatory Blood PressureInternational Study. Hypertension. 2014;64:487-93.

43. Li Y, Thijs L, Hansen TW, Kikuya M, Boggia J, Richart T, et al. Prognostic value of the morning blood pressure surge in 5645 subjects from 8 populations. Hypertension. 2010;55:1040-8.

44. Alessi A, Alessi CR, Piana ER, Assis M, Oliveira LR, Pereira da Cunha CL. Influência da qualidade do sono na queda noturna da pressão arterial durante monitorização ambulatorial da pressão arterial. Arq Bras Cardiol. 2002;78:212-7. 